\title{
Cardiovascular disease among patients admitted to medicine intensive care unit (MICU) in tertiary care hospital
}

\author{
Arpith M. N. ${ }^{1}$, Revathi Devi M. L., ${ }^{2,}$, Purushothama S. M. ${ }^{3}$, Manju Natha S. N. ${ }^{4}$ \\ ${ }^{1}$ PG Student, ${ }^{2}$ Professor \& HOD, ${ }^{3,4}$ Assitant Professor, ${ }^{\mathbf{1 , 2 , 3}}$ Dept. of Physiology, ${ }^{4}$ Dept. of Community Medicine, Mysore Medical \\ College \& Research Institute, Mysuru, Karnataka, India
}

*Corresponding Author:

Email: drrevathidevi1@gmail.com

Received: $19^{\text {th }}$ January, 2018

Accepted: $12^{\text {th }}$ March, 2018

\begin{abstract}
Introduction: Cardiovascular diseases (CVD's) are rampantly increasing in the Indian population with an increasing trend in the younger patients. Overall cardiovascular diseases showed that almost one-fourth of all deaths in India in 2008. CVD's were considered as the fastest growing chronic illness between 2005 and 2015, growing at an average of $9.2 \%$ per year.

Objectives: (i) To know cardiovascular diseases in patients admitted to MICU; (ii) Categorization of various CVD and associated conditions; (iii) To know the socio demographic profile of the patients.

Materials and Methods: The study was retrospective of 3 months duration among patients of age group among 30-50 years admitted in KR Hospital Mysuru. All the patients admitted in the hospital for a minimum duration of 24 hours were included. Data were collected based on standard proforma from the available case record sheets. The analysis of data was based on descriptive statistical analysis.

Results: The study found that majority of cases recorded in MICU was cardiovascular related disorders. In that Myocardial infraction (MI) was major cardiovascular disease (CVD)
\end{abstract}

Keywords: Medicine intensive care unit (MICU), Myocardial infarction (MI), Cardiovascular diseases(CVD).

\section{Introduction}

The Medicine Intensive Care Unit (MICU) is a part of hospital setup providing emergency health care for adult and geriatric critically ill medical patients having conditions related to lung, kidney, liver, cardiovascular diseases, cancer septicemia. Cardiovascular disease(CVD) includes coronary artery diseases (CAD) such as angina and myocardial infarction $(\mathrm{MI})^{1}$ other CVD are stroke, hypertension, rheumatic heart disease, cardiomyopathy, arrhythmia, congenital, valvular heart disease, carditis, aortic aneurysms, peripheral artery disease and venous thrombosis. ${ }^{[1][2]}$. Cardiovascular disease is one of the leading cause of death worldwide. ${ }^{1}$ Together they resulted in 1.73 crore deaths $(31.5 \%)$ in 2013 up from 1.23 crores (25.8\%) in $1990 .^{2}$ Since from 1970s Cardiovascular mortality rate are increasing in developing countries, while rates have declined in most of the developed countries. ${ }^{3,4}$ World Health Organization (WHO) reported the age standardized CVD mortality rate among males and females in India is 363-443 and 181-281, (per 1,00,000 population) respectively. According to $\mathrm{WHO}$, non-communicable diseases estimate $53 \%$ of total mortality rates in Indian population and $24 \%$ accounts for CVD. ${ }^{5}$ This study helps to know the burden of diseases being treated in MICU. It helps in understanding the epidemiology of cardiovascular diseases with mortality and morbidity in the Mysuru region and also the infrastructure of MICU.

\section{Objectives}

i. To know the number of CVD patients admitted to MICU.

ii. Categorization of various CVD and associated conditions.

iii. To know the socio demographic profile of the CVD patients.

\section{Materials and Methods}

It is a retrospective study; total 115 patients admitted in MICU were included in this study.

\section{Inclusion criteria:}

1. All the patients admitted in MICU at least for 15 days mainly involving CVD.

2. Age group between 30-50 years.

3. Other systemic diseases involving CVD.

4. Chronic smokers (Males)

\section{Exclusion criteria:}

1. Age criteria not more than 50 years.

The study was retrospective collection of case report data for 3 months in age group 30-50 years. The study only included cardiovascular conditions for the detailed analysis. If the patient is having multiple diagnosis and cause will be included in the study. The data collection will be as per the standard proforma. The retrospective study involves collection of data based on the available records related to MICU in the medical record section. Descriptive statistics will be 
used for the analysis of the case report data according to international classification of diseases 9 .

\section{Results}

A total of 115 patients were included in the study as per the available records. $71(61.73 \%)$ patients had cardiovascular related conditions, followed by 32 $(27.82 \%)$ had respiratory, $10(8.69 \%)$ CNS and 2 (1.73\%) renal related problems (Table 1). Majority of the patients had combined systemic related problems (Fig. 1). CVD were more common in men 41(58\%) compared to women $30(42 \%)$ (Figure 2) and age distribution among study patients (Table 2).

Out of 71 CVD cases the recovery rate was $55(77 \%)$ and mortality was 16 (23\%). Myocardial infarction 50(70\%) was major CVD followed by Congestive Cardiac Failure (CCF) 10(14\%), Cardiovascular Accidents (CVA) 6(8\%) and Arrhythmias 5(7\%) (Graph 3)

Socioeconomic status was assessed according to BG Prasad Classification, where out of total 115 patients, $15(13.04 \%)$ were upper middle class, 70 $(60.87 \%)$ were middle class and $30(26.09 \%)$ were lower middle class (Table 4).

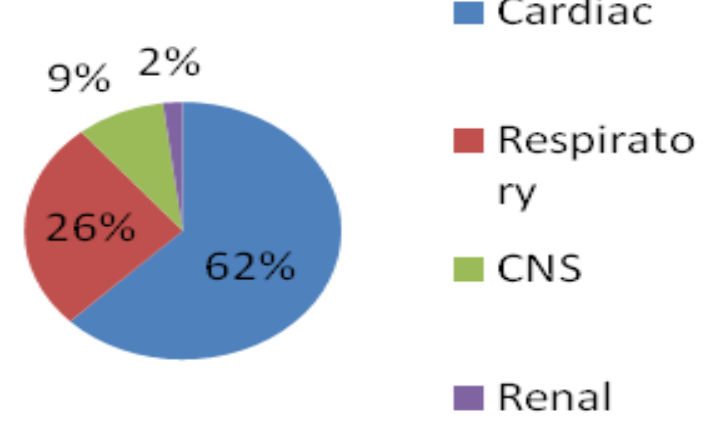

Fig. 1: System wise distribution of patients admitted in MICU $(n=115)$

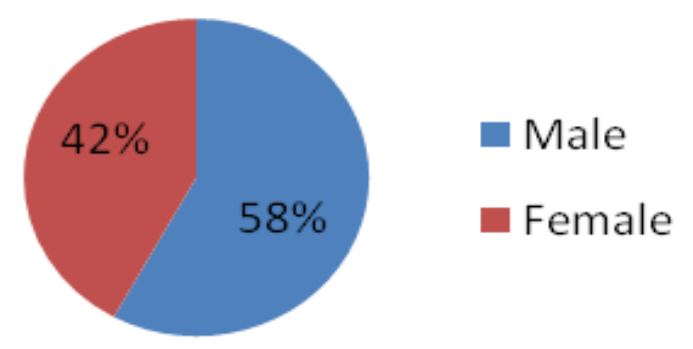

Fig. 2: Gender distribution of CVD $(n=71)$

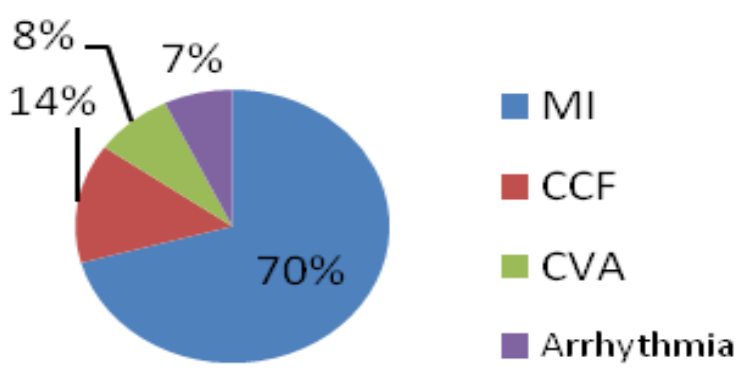

Fig. 3: Forms of CVD' distribution $(n=71)$

\section{Discussion}

A discouraging fact is that the incidences of CVD have increased significantly in the age group between $25-69$ years to $24.8 \% .^{2}$ It is important to track down and closely monitor the prevalence of CVD and with better intervention protocols aimed at proper education, prevention, control and treatment of the disease. In India, the exponential rise in prevalence of heart disease in younger population needs to be considered. ${ }^{6,7}$

A study conducted by Thegalem Hailemariam on Prevalence of Cardiovascular Emergencies in Specialized Hospital, Addis Ababa Ethiopia suggested that the prevalence of cardiovascular emergency in the emergency room was $11 \%$ of medical emergency and majority $(40 \%)$ presented with Rheumatic valvular heart diseases followed by Hypertension (26\%) and Ischemic heart diseases $(15 \%)$ and they were in emergency because majority (44\%) had CCF followed by Stroke (22\%) and Cardiac arrest (11\%). ${ }^{9}$ This study is having a difference in its statistical data suggesting that distribution depends on demography.

Cocaine drug abuse is one of the main reasons for the non-traumatic chest pain and can result in MI in the younger age group ${ }^{8}$. Better prognosis among young patients is achieved by appropriate investigation and treatment offered. Life style changes play important role in all non-communicable diseases. Complete cessation of smoking should be strongly advised.

Table 1: System wise disease distribution in MICU

\begin{tabular}{|l|c|}
\hline \multicolumn{1}{|c|}{ System involved } & Number of patient (\%) \\
\hline Cardiovascular & $71(61.73 \%)$ \\
\hline Respiratory & $32(27.82 \%)$ \\
\hline CNS & $10(8.69 \%)$ \\
\hline Renal system & $02(1.73 \%)$ \\
\hline Total & $115(100 \%)$ \\
\hline
\end{tabular}

Table 2: Age group wise distribution in all MICU patients

\begin{tabular}{|l|c|c|c|}
\hline Age in years & Male & Female & Total (\%) \\
\hline $30-35$ & 10 & 06 & $16(\%)$ \\
\hline $35-40$ & 12 & 09 & $21(\%)$ \\
\hline $40-45$ & 20 & 14 & $34(\%)$ \\
\hline $45-50$ & 24 & 20 & $44(\%)$ \\
\hline Total & 66 & 49 & $115(100 \%)$ \\
\hline
\end{tabular}


Table 3: Cardiovascular diseases distribution among MICU patients

\begin{tabular}{|l|c|}
\hline \multicolumn{1}{|c|}{ Cardiovascular diseases } & $\begin{array}{c}\text { Number of patient } \\
(\%)\end{array}$ \\
\hline Myocardial Infarction (MI) & $50(70.422 \%)$ \\
\hline $\begin{array}{l}\text { Congestive Cardiac } \\
\text { Failure(CCF) }\end{array}$ & $10(14.084 \%)$ \\
\hline $\begin{array}{l}\text { Cardiovascular Accidents } \\
\text { (CVA) }\end{array}$ & $06(08.450 \%)$ \\
\hline Cardiac Arrhythmias & $05(07.042 \%)$ \\
\hline Total & $71(100 \%)$ \\
\hline
\end{tabular}

Table 4: Demographic Profile

\begin{tabular}{|l|c|}
\hline \multicolumn{1}{|c|}{ Socioeconomic status } & $\begin{array}{c}\text { Number of patient } \\
(\mathbf{\%})\end{array}$ \\
\hline Upper middle class & $15(13.04 \%)$ \\
\hline Middle class & $70(60.87 \%)$ \\
\hline Lower middle class & $30(26.09 \%)$ \\
\hline Total & $115(100 \%)$ \\
\hline
\end{tabular}

\section{Conculsion}

Majority of the patients receving treatment at MICU was suffering from cardiovascular conditions. MI was the major cardiovascular condition among the study population. Cardiovascular diseases were more prevelant among young adults. It is strongly emphaise the importantance of secondary preventive measures in all young patients admitted in medicine intensive care unit with myocardial infraction as the long term mortality can reach one third if not treated appropriately.

To conclude, CVD are slowly reaching out to all sections of the society. Large scale and widespread incidence shows downgrading of the cardiovascular health status of Indians and emergence of CVD as a chronic manifestation across the population. This affects the country's productivity owing to economic burden in an otherwise beneficial phase of demographic transition. Need of the hour is to track down and closely monitor the prevalence of disease and tackle it with aggressive, effective and efficient intervention policies that aim at prevention, control and treatment of CVD in all sections of the population. More efforts are needed to encounter the epidemic at the level of risk factor prevalence. Also, more targeted and comprehensive policies need to be extended to the masses for healthcare financing.

\section{References}

1. Shanthi Mendis; Pekka Puska; Bo Norrving;World Health Organization (2011). Global Atlas on Cardiovascular Disease Prevention and Control (PDF). World Health Organization in collaboration with the World Heart Federation and the World Stroke Organization. pp. 318. ISBN 978-92-4-156437-3.

2. GBD 2013 Mortality and Causes of Death, Collaborators (17 December 2014). "Global, regional, and national agesex specific all-cause and cause-specific mortality for 240 causes of death, 1990-2013: a systematic analysis for the Global Burden of Disease Study 2013". Lancet 2015 Jan 10;385(9963):117-71. DOI:10.1016/S0140-6736(14)616822.PMC 4340604. PMID 25530442.

3. Fuster, Board on Global Health; Valentin; Academies, Bridget B. Kelly, editors; Institute of Medicine of the National (2010). Promoting cardiovascular health in the developing world: a critical challenge to achieve global health. Washington, D.C.: National Academies Press. pp. Chapter 2. ISBN 978-0-309-14774-3.

4. Moran, AE; Forouzanfar, MH; Roth, GA; et al. "Temporal trends in ischemic heart disease mortality in 21 world regions, 1980 to 2010: the Global Burden of Disease leScholar2010 study". Circulation.2014 April 8;129(14):1483-92.

5. Tanmay nag and Arnab ghosh. J Cardiovasc Dis Res. 2013 Dec;4(4):222-8.

6. Bhatnagar D, Anand IS, Durrington PN, et al. Coronary risk factors in people from Indian sub- continent living in west London and their siblings in India. Lancet $1995 \mathrm{Feb}$ 18;345(8947):405-9.

7. Enas EA, Mehta J. Malignant coronary artery disease in young Asian Indians: thoughts on pathogenesis, prevention and therapy. Clin Cardiol 1995 Mar;18(3):131-5.

8. Jay SJ. Cocaine use and chest pain syndromes. Arch Intern Med 1998 Sep 14;158(16):1827-8.

9. Tsegalem Hailemariam. Prevalence of Cardiovascular Emergencies in Specialized Hospital, Addis Ababa Ethiopia. Emergency Med 4:198.2014. 